\title{
دراسة اقتصادية للكفاءة التسويقية لمحصول القمح في محافظة الغربية
}

شحاته عبد المقصود غنيم ، محمد عبد الستار مبارك ، مفيدة السيد قابيل ، هالة شوقي حربي

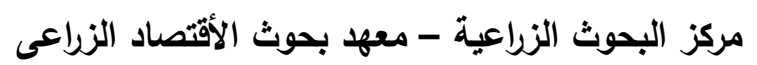

Received: Sep. 26,2021

Accepted: Oct. 30, 2021

المستخلص

يهدف هذا البحث إلى محاولة التظلب على المشاكل والمعوقات التي تواجه منتجي القمح في تسويق إنتاجهم، وذلك التكات

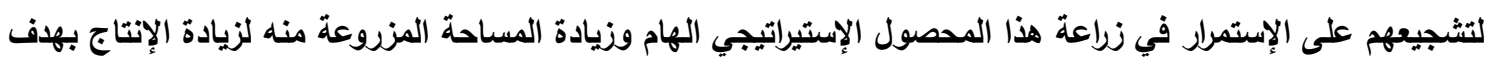
تقليل الفجوة الغذائية القحية ويالتالي زيادة نسبة الإكتفاء الذاتي من محصول القمح. ولتحقيق هذا الهيف تم دراسة وتقدير الكفاءة التسويقية لهذا المحصول في مختلف المسالك التسويقية، حيث بلغت الكفاءة التسويقية في المسلك الأول

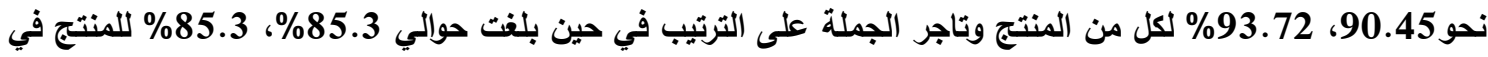
المسلكين الثاني والثالث، أما عن أهم مشاكل ومعوقات تسويق محصول القمح فتضم مجموعتين تتعلق الأولى بسعر

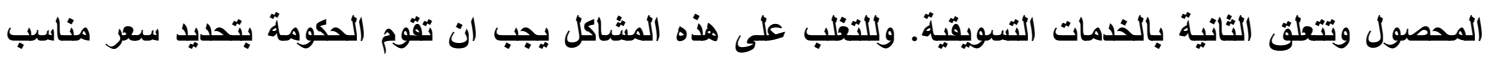
لأردب القمح وحماية المزارعين من تحكم التجار في تحديد سعر الثراء وتسديد ثمن المحصول للمزارعين بسرعة وأخيراً توفير وسائل نقل مناسبة ورخيصة لخدمة المزارعين، والعمل على توفير أماكن في القرى لإستلام المحصول من المزارعين. الكلمات المفتاحية: الكفاءة التسويقية - المسالك التسويقية - التكاليف التسويقية - الهامش التسويقي- المشاكل والمعوقات التسويقية.

كما يعتبر محصول القمح من المحاصيل

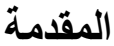

الإستيراتيجية الهامة في مصر لما له من أهمية كبيرة في من الهيح الأمن الغذائي والتجارة الخارجية، حيث يتم إستيراد كميات كبيرة من الخارج وذلك لسد الفجوة الغذائية القمحية، حيث يمثل القمح الغذاء الأساسي للإنسان في مصر. وعملية تسويق محصول القمح من العمليات التي تثثظل إهتمام مزارعي هذا المحصول كل عام حيث أن

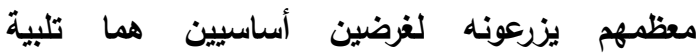
إحتياجاتهم الغذائية وتصريف وييع الباقي من الإنتاج للحصول على دخل يساعدهم في مواجهه منطلبات الغيات

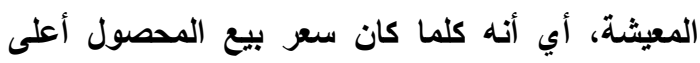
كلما كان ذلك مشجعاً للمزارعين على الإستمرار في النه زراعته وزيادة المساحة المزروعة منه، مما يؤدي بالتالي الأيني إلى تقليل الفجوة الغذائية القمية، وكذا تقليل العبء
يعتبر القمح المحصول الغذائي الرئيسي في مصر للسكان في الريف والحضر ولذا يطلق عليه المحصول المعيثي الأول، كما تعتمد صناعات غذائية على القمح

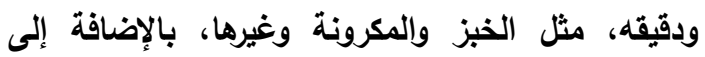
المنتجات الثانوية للقمح وهى النخالة والتبن اللأن يستخدمان في تغذية الحيوانات. لذا فقد تزايدت المساحة المزروعة بمحصول القمح من 2.34 مليون فداناً عام

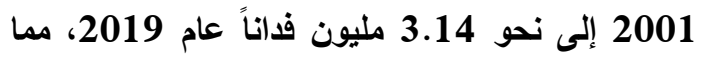
ترتب عليه زيادة في الإنتاج الكلي من نحو 6.409 مليون طناً عام 2001 إلى نحو 8.559 مليون طناً عام 2019 خلال نفس الفترة بإنتاجية بلغت حوالي أكثر من 3 مليون طن للمليون فدان عام 2001 مقابل 2 مليون طن لمليون فدان عام 2019. 
تبذلها الدولة متمثلة في التوسع في زراعة محصول

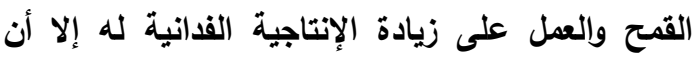

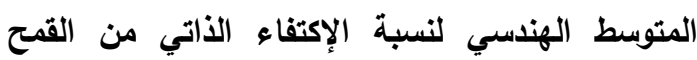
منخفض حيث يمثل نحو 53.57\% خلال فترة البحث

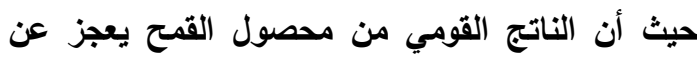

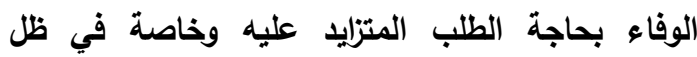

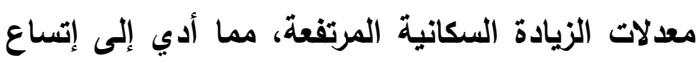

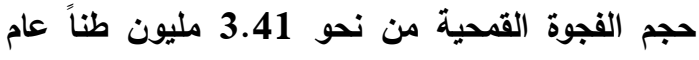

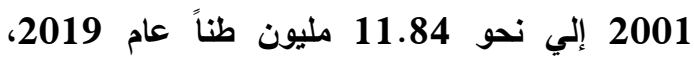

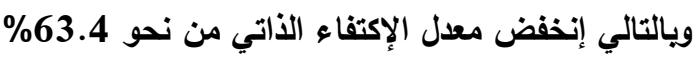

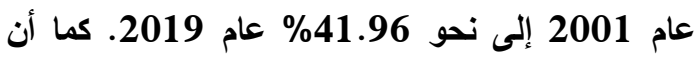
السياسة الزراعية في مصر بصفة عامة لا تعطي للجاتب التسويقي إهتماماً كافياً، حيث يواجه منتجو المحاصيه عامهيل الحقلية بصفة عامة مشاكل تسويقية في تصريف منتجاتهم. ويتعرض النظام التسويقي لتقلبات إنتاجية

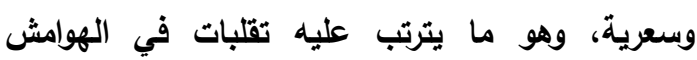

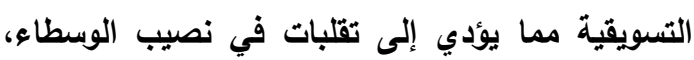
وكلما زادت هذه التقلبات كلما إنخفضت الكفاعة التسويقية نتيجة إرتفاع التكاليف التسويقية. أهداف البحث:

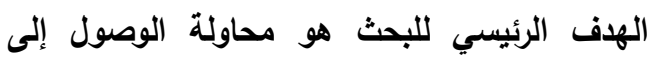

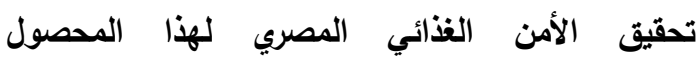
الإستيراتيجي الأول ولتحقيق هذا الهاف لابد من دراسة الأهداف الفرعية التالية:1-دراسة السياسة التسويقية لمحصول القمح. 2-تقلير الكفاءة التسويقية في المسالك التسويقية المختلفة لمحصول القمح. 3-مشاكل ومعوقات تسويقه ومقترحات حل هذه لهن

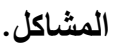

مصادر البيانات إعتمد البحث على مصدرين للبيانات، المصدر الأول منهما بيانات ثانوية منشورة وغير منشورة صادرة من الإدارة المركزية للإقتصاد الزراعي بوزارة الزراعة، الجهاز
الواقع على الدولة في توفير العملة الصعبة اللازمة لإستيراد القمح من الخارج.

والسياسة الزراعية في مصر بصفة عامة لا تعطي

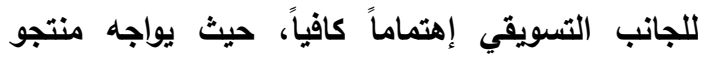
المحاصيل الحقلية بصفة عامة مشاكل تسويقية في تصريف منتجاتهم. ويتعرض النظام التسويقي لتقلبات إنتاجية وسعرية، وهو ما يترتب عليه تقلبات في ونئن

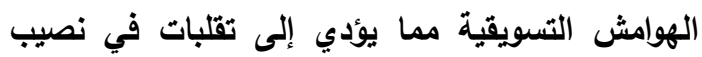
الوسطاء، وكلما زادت هذه التقلبات كلما إنخفضت الكفاءة التسويقية نتيجة إرتفاع التكاليف التسويقية.

أما عن السياسة التسويقية لمحصول القمح فقد تأثرت بالتحرر الكامل في القطاع الزراعي الذي بدأ منذ

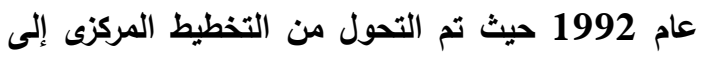

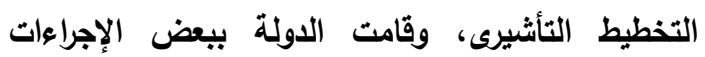

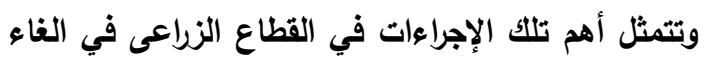

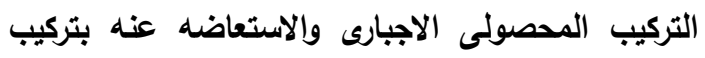
محصولى تأثيرى وفقاً لرغبات المزارعين واحتياجاتهم

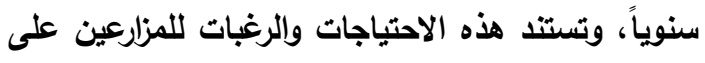
الريحية النسبية لمختلف المحاصيل المزروعة في كل

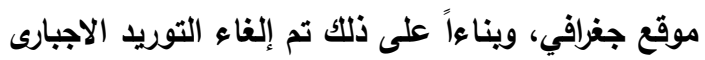

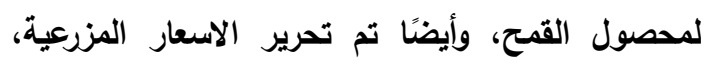

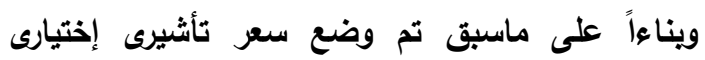
لمحصول القمح سنوياً، وتقوم وزارة الزراعة بتحديد السعر التأثيرى كل سنة على حسب درجة الجودة. وسوف يتناول هذا البحث كلاً من 1- السياسة التسويقية لمحصول القمح 2- كيفية تقدير الكفاءة التسويقية في المسالك التسويقية لهذا لهدئه المصول

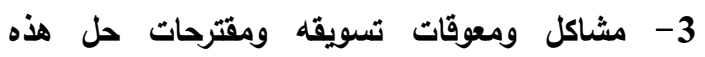

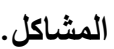
مشكلة البحث يتناول البحث ما يتعلق بتسويق محصول القمح، لما

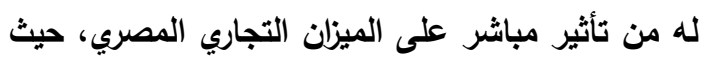

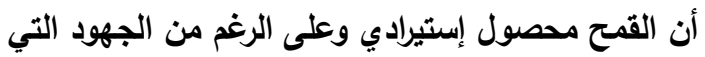


An economic study of the marketing efficiency of wheat crop in Gharbia ....

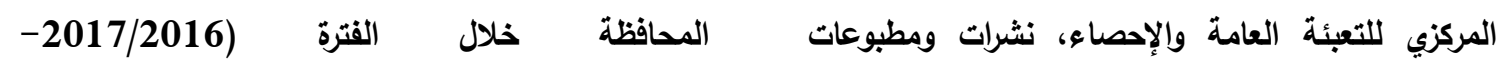
2019/2018) حوالي 124.48 ألف فداناً يمثل نحو 4.05 من إجمالي المساحة المزروعة منه على

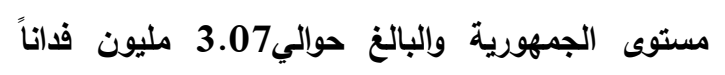

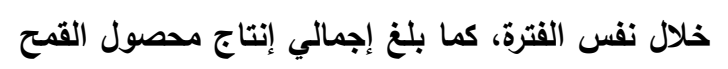
بمحافظة الغربية حوالي 333.506 ألف طناً خلال الفترة السابقة يمثل نحو 3.95\% من إجمالي إنتاج المحصول على مستوى الجمهورية والبالغ نحو 8.44 مليون طناً في خلال نفس الفترة. بالإضافة إلى ما سبق فإنى إنى محافظة الغربية هي محل عمل وإقامة الباحثين ومعاونيهم القائمين بإعداد الدراسة مما يؤدي إلى سهولة هيلة الحصول على البيانات الحقيقية اللازمة للاراسة وزيادة درجة الثقة فيها.

(2) إختيار مراكز العينة وتقدير عدد الحائزين المختارين من مزارعي محصول القمح بهذه المراكز : تم إختيار مركزي طنطا والمحلة الكبري من بين مراكز مزارعي ملهول

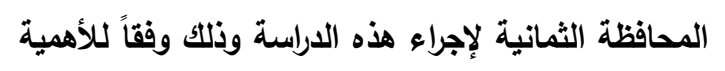

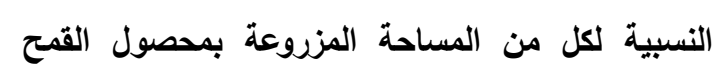

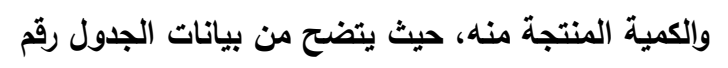

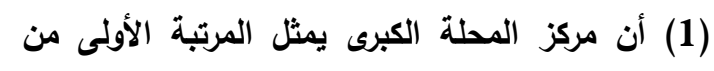

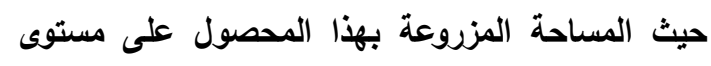

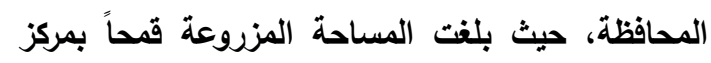

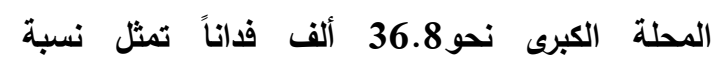
\%25.45 من إجمالي المساحة المزروعة بمحصول

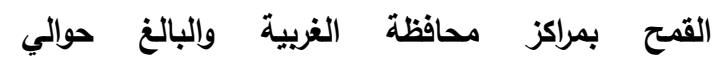
144.557 ألف فداناً عام 2020/2019، بينما يمثل مركز طنطا المرتبة الثانية من حيث المساحة المزروعة المبام

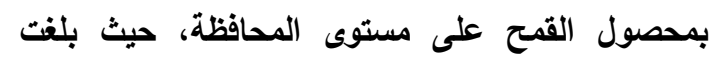

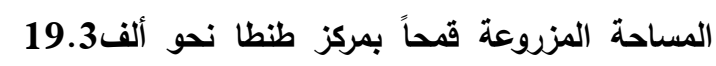

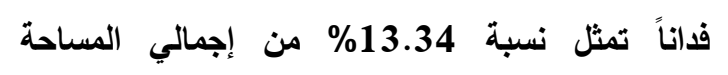
المزروعة بمحصول القمح بمراكز المحافظة في نفس فئل فئل 
Sh. A. Ghoneim, et al.,

$$
1.03=\frac{56073}{43240}=
$$

S = 0.635

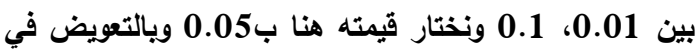

القانون السابق عن قيمة كل من C.V، X X

حيث تمثل S الإنحراف المعياري C.V معامل الإختلاف

$$
0.05=\frac{0.635}{\sqrt{n}} \quad \div 1.03
$$

$\mathrm{n}=95.43 \sim 95$
ويتضح من بيانات الجدول رقم (2) كيفية تقدير عدد الحائزين المختارين من مزارعي محصول القمح بمركزي الاراسة الميدانية بمحافظة الغربية وذلك بإستخدام طريقة الوسط الهنسي المعدل، حيث بلغ عدد الحائزين المختارين نحو 61، 34 حائزاً من كل من مركزي المحلة الكبرى وطنطا علي الترتيب. ويتم حساب حجم العينة من القانون التالي: (2) C.V $=\frac{s}{\sqrt{n}} \div \mathbf{x}$ المتوسط الحسابي(X)=

\begin{tabular}{|c|c|c|c|c|c|c|c|c|c|c|}
\hline الإجمالي & سمنود & الكبرى & بسيون & كفر & زفتى & السنطة & قطور & طنطا & & \\
\hline 144557 & 9766 & 36795 & 14043 & 12793 & 17245 & 17291 & 17346 & 19278 & بالقدان & المساحة \\
\hline 100 & 6.76 & 25.45 & 9.71 & 8.85 & 11.93 & 11.96 & 12 & 13.34 & \% إلجماليّ & المزروعة \\
\hline
\end{tabular}

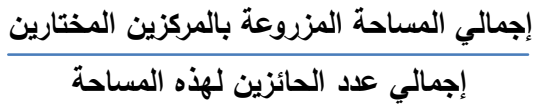

جدول رقم (1): الأهمية النسبية للمساحة المزروعة بمصصول القمح بمراكز محافظة الغربية في العام الزراعي 2020/2019.

\begin{tabular}{|c|c|c|c|c|c|c|c|c|}
\hline & & & \multicolumn{6}{|c|}{ الغربية في العام الزراعي (2020/2019). } \\
\hline \multirow{2}{*}{ المختائزين } & \multirow{2}{*}{ الهندسي } & \multirow{2}{*}{ الهندسي } & \multicolumn{2}{|c|}{ 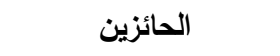 } & \multicolumn{2}{|c|}{ المساحة المزروعة } & & \multirow[t]{2}{*}{ p } \\
\hline & & & $\%$ & عدد & $\%$ & فدان & & \\
\hline 61 & 64.34 & 64.31 & 63.03 & 27255 & 65.62 & 36795 & المحلة الكبرى & 1 \\
\hline 34 & 35.66 & 35.65 & 36.97 & 15985 & 34.38 & 19278 & طنطا & 2 \\
\hline 95 & 100 & 99.96 & 100 & 43240 & 100 & 56073 & ي المركزين & \\
\hline
\end{tabular}

المصدر:- مديرية الزراعة بالغريبة، سجلات إدارة الإحصاء، بيانات غير منشورة.

جدول رقم (2): تقدير عدد الحائزين المختارين من مزارعي محصول القمح بمركزي الاراسة المختارين من محافظة

حيث:

الوسط الهنسي لكل مركز = الجذر التربيعي لحاصل ضرب النسبة المئوية للمساحة المزروعة قحاً بالمركز × نسبة عدد الحائزين لهذه المساحة بالمركز

الوسط الهنسي المعدل للمركز= الوسط الهندسي للمركز / إجمالي الوسط الهندسي للمركزين ×100 عدد الحائزين المختارين من المركز = الوسط الهندسي المعدل للمركز × حجم العينة / 100 
سليم وشوني من مركز طنطاحيث تبين أن جملة المساحة المزروعة بمحصول القمح في هاتين القريتين تبلغ نحو2379 فداناً تمثل نحو 12.34\% من إجمالي المساحة المزروعة بهذا المحصول في مركز طنطا والبالغ نحو 19278فداناً في نفس العام. ويتضح من بيانات الجدول رقم (4) كيفية تقدير

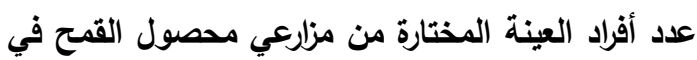
القرى السابق ذكرها وذلك بإستخدام طريقة الوسط الهندسي المعدل حيث بلغ عدد الحائزين المختارين من

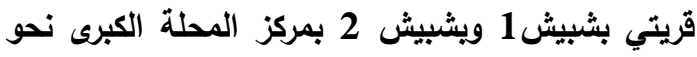

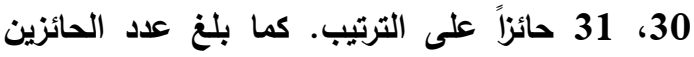
المختارين من قريتي فيشا سليم وشوني بمركز طنطا نحو

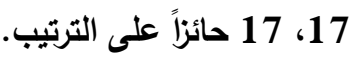

(3) إختيار قرى العينة وتقدير عدد الحائزين المختارين منها:

تم إختيار قريتين من كل مركز من مركزي الدراسة

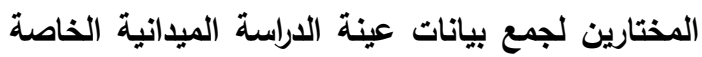
بتسويق محصول القمح، وذلك حسب الأهمية النسبية للمساحة المزروعة من هذا المحصول بكل قرية من القريتين فى كل مركز، حيث يتضح من بيانات جدول رقم (3) انه تم إختيار قريتي بشبيش1 1 ويشبيش2 من مركز المحلة الكبرى، حيت يتبين أن جملة المساحة المزروعة في هاتين القريتين تبلغ نحو 3455 فداناً تمثل نحو 9.4 \% من إجمالي المساحة المزروعة بهذا المحصول

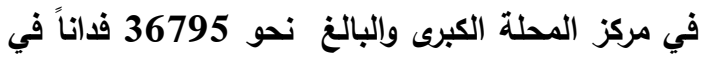
العام الزراعي 2020/2019، كما تم إختيار قريتي فيثا

جدول رقم (3): الأهمية النسبية للمساحة المزروعة بمحصول القمح بقرى عينة الاراسة الميدانبة المختارة من محافظة الغربية في العام الزراعي 2020/2019.

\begin{tabular}{|c|c|c|c|c|c|c|c|}
\hline \multicolumn{2}{|c|}{ المساحة المزروعة قمحاً } & \multirow[t]{2}{*}{ القرية } & \multirow[t]{2}{*}{ المركز } & \multicolumn{2}{|c|}{ المساحة المزروعة قحاً } & \multirow[t]{2}{*}{ القرية } & \multirow[t]{2}{*}{ المركز } \\
\hline إجمالي المركز & بالفدان & & & \% من إجمالي & بالفدان & & \\
\hline 6.16 & 1188 & فيشا سليم & \multirow[t]{3}{*}{ طنطا } & 4.5 & 1655 & بشبيش1 & \multirow[t]{3}{*}{ المحلة الكبرى } \\
\hline 6.18 & 1191 & \multirow[t]{2}{*}{ شوني } & & 4.9 & 1800 & بشبيش2 & \\
\hline \multirow[t]{2}{*}{12.34} & 2379 & & & 9.4 & 3455 & إجمالي القريتين & \\
\hline & 19278 & \multicolumn{2}{|c|}{ إجمالى المركز } & & 36795 & & إجمالى المركز \\
\hline
\end{tabular}

المصدر:- جمعت وحسبث من سجلات قسم الإحصاء- مديرية الزراعة بالغربية- الإدارة الزراعية بكل من مركزي المحلة الكبرى وطنطا

$$
\text { - بيانات غير منشورة. }
$$

جدول رقم (4): تقدير عدد أفراد العينة المختارة من مزارعي محصول القمح في القرى المختارة من مركزي المحلة الكبرى ، طنطا بمحافظة الغربية في العام الزراعي $2020 / 2019$.

\begin{tabular}{|c|c|c|c|c|c|c|c|c|}
\hline \multirow{2}{*}{ عداد أفراد } & \multirow{2}{*}{ الوسط الهندسي } & \multirow{2}{*}{ الهندسي } & \multicolumn{2}{|c|}{ الحائزين } & \multicolumn{2}{|c|}{ المساحة المزروعة } & & \multirow[t]{2}{*}{ المركز } \\
\hline & & & \% من إجمالي & عدد & \% من إجمالي & فدان & & \\
\hline 30 & 48.75 & 48.74 & 49.6 & 1062 & 47.9 & 1655 & بشبيش1 & \multirow{3}{*}{ الكبرى } \\
\hline 31 & 51.25 & 51.24 & 50.4 & 1079 & 52.1 & 1800 & بشبيش2 & \\
\hline 61 & 100 & 99.98 & 100 & 2141 & 100 & 3455 & إجمالي القريتين & \\
\hline 17 & 49.5 & 49.5 & 49.1 & 711 & 49.9 & 1188 & فيثا سليم & \multirow[t]{3}{*}{ طنطا } \\
\hline 17 & 50.5 & 50.5 & 50.9 & 737 & 50.1 & 1191 & شونى & \\
\hline 34 & 100 & 100 & 100 & 1448 & 100 & 2379 & إجمالي القريتين & \\
\hline 95 & \multicolumn{8}{|c|}{ الإجمالـي } \\
\hline
\end{tabular}

حيث:- الوسط الهندسي المعدل للمركز= الوسط الهندسي للمركز / إجمالي الوسط الهنسسي للمركزين ×100 عدد أفراد العينة المختارة من القرية = الوسط الهندسي المعدل للقرية × إجمالي عدد أفراد العينة المختارة من القريتين/100 المصدر:- سجلات قسم الإحصاء بالإدارات الزراعية والجمعيات الزراعية بالقرى المختارة - بيانات غير منشورة. 
Sh. A. Ghoneim, et al.,

ويإستخدام الوسط الهنسي المعدل لعدد الحائزين

توزيع العينة المختارة على الفئات الحيازية داخل والمساحة الحيازية لكل فئة تم تقدير وتوزيطيع عينة الدراسة على هذه الفئات كما هو واضح في بيانات جدولي رقم (5)، رقم (6) بواقع 41، 34، 34، 20 مزارعاً من كل من الفئات الأولي، الثانية والثالثة تمثل بولة \%33.16، 35.79\%، 21.05\% على الترتيب من الحجم الكلي للعينة والبالغ 95 مفردة.

بعد تقدير عدد أفراد العينة المختارة من مزارعي محصول القمح في قرى العينة، تم تقسيم الحائزين داخل فئل فزئل كل قرية إلى ثلاث فئات حيازية تثمل الفئة الأولى الفي

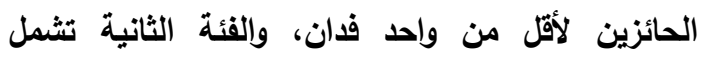
الحائزين لمساحة واحد فدان إلى أقل من ثثلاثة أفندة أما

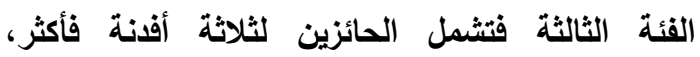

جدول رقم (5): كيفية توزيع أفراد العينة المختارة من مزارعي محصول القمح على الفئات الحيازية بقرى عينة الاراسة

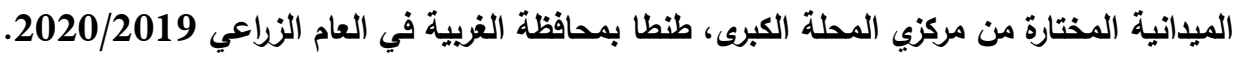

\begin{tabular}{|c|c|c|c|c|c|c|c|c|c|}
\hline \multirow{2}{*}{ 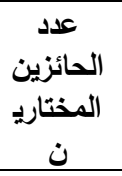 } & \multirow{2}{*}{ الألوسط المعدي } & \multirow{2}{*}{ الهندسي } & \multicolumn{2}{|c|}{ الحائزين } & \multicolumn{2}{|c|}{ المساحة المزروعة } & \multirow[t]{2}{*}{ الفئات الحيازية } & \multirow{2}{*}{ القختارة } & \multirow[t]{2}{*}{ المركز } \\
\hline & & & $\begin{array}{c}\% \\
(2)\end{array}$ & عدد & $\begin{array}{c}\% \\
(1)\end{array}$ & فدان & & & \\
\hline 14 & 30.39 & 27.75 & 46.33 & 492 & 16.62 & 275 & أقل من واحد فدان & \multirow{4}{*}{ بشبيش } & \multirow{8}{*}{ الكبرى } \\
\hline 11 & 38.50 & 35.15 & 35.88 & 381 & 34.44 & 570 & من 1-3 أفننة & & \\
\hline 5 & 32.31 & 29.50 & 17.80 & 189 & 48.94 & 810 & من 3 افدنة فاكثر & & \\
\hline 30 & 101.2 & 91.30 & 100 & 1062 & 100 & 1655 & إجمــــــــــــالي & & \\
\hline 15 & 31.67 & 28.88 & 50.05 & 540 & 16.67 & 300 & أقل من واحد فدان & \multirow{4}{*}{ بشبيش } & \\
\hline 11 & 37.72 & 34.40 & 33.82 & 365 & 35 & 630 & من 1 - 3 أفدنة & & \\
\hline 5 & 30.61 & 27.92 & 16.13 & 174 & 48.33 & 870 & من 3 افنة فاكثر & & \\
\hline 31 & 100 & 91.20 & 100 & 1079 & 100 & 1800 & 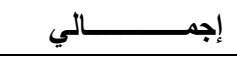 & & \\
\hline 61 & & & & 2141 & & 3455 & \multicolumn{3}{|c|}{ إجمـالي القـرى المختــارة من المـركز } \\
\hline 6 & 34.42 & 31.43 & 49.93 & 355 & 19.78 & 235 & أقل من واحد فدان & \multirow{4}{*}{ سيثا } & \multirow[t]{8}{*}{ طنطا } \\
\hline 6 & 33.14 & 30.26 & 33.47 & 238 & 27.36 & 325 & من 1 - 3 أفدنة & & \\
\hline 5 & 32.44 & 29.62 & 16.60 & 118 & 52.86 & 628 & من 3 افندة فاكثر & & \\
\hline 17 & 100 & 91.31 & 100 & 711 & 100 & 1188 & ــــالي & & \\
\hline 6 & 31.72 & 28.92 & 39.80 & 367 & 16.8 & 200 & أقل من واحد فدان & \multirow[t]{4}{*}{ شوني } & \\
\hline 6 & 36.63 & 33.40 & 33.51 & 247 & 33.3 & 397 & من 1 - 3 أفدنة & & \\
\hline 5 & 31.65 & 28.86 & 16.69 & 123 & 49.9 & 594 & من 3 افدنة فاكثر & & \\
\hline 17 & 100 & 91.18 & 100 & 737 & 100 & 1191 & 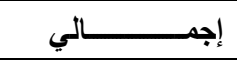 & & \\
\hline 34 & & & & 1448 & & 2379 & \multicolumn{3}{|c|}{ إجمـالي القـرى المختــارة من المـركز } \\
\hline 95 & & & & 3589 & & 4654 & \multicolumn{3}{|c|}{ إجمـــــــــــالي قــــــى العينة } \\
\hline
\end{tabular}

حيث: (1) تعني نسبة المساحة المزروعة قمحاً في كل فئة حيازية بالقرية المختارة إلى إجمالي المساحة المزروعة قمحاً في نفس (2) تعني نسبة عدد الحائزين للمساحة المزروعة قمحاً في كل فئة حيازية بالقرية المختارة إلي إجمالي عدد الحائزين 
An economic study of the marketing efficiency of wheat crop in Gharbia ....

المصدر:- سجلات قسم الإحصاء بالإدارات الزراعية والجمعيات الزراعية بالقرى المختارة - بيانات غير منشورة.

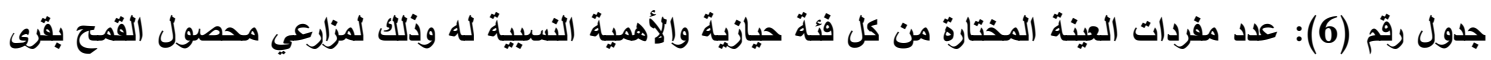

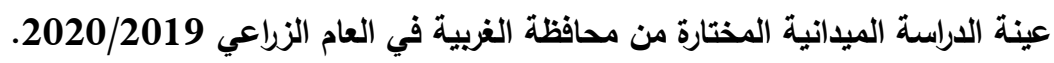

\begin{tabular}{|c|c|c|c|c|c|}
\hline الإجمالي & من 3 أفدنة فأكثر & من 1-3 (فدنة & أقل من واحد فدان & الفئة & \\
\hline 30 & 5 & 11 & 14 & \multicolumn{2}{|r|}{ بشبيش1 } \\
\hline 31 & 5 & 11 & 15 & \multicolumn{2}{|r|}{ بشبيش2 } \\
\hline 17 & 5 & 6 & 6 & \multicolumn{2}{|r|}{ فيشا سليم } \\
\hline 17 & 5 & 6 & 6 & \multicolumn{2}{|r|}{ شوني } \\
\hline 95 & 20 & 34 & 41 & عـــدد & \multirow[t]{2}{*}{ الإجمالي } \\
\hline 100 & 21.05 & 35.79 & 43.16 & \% من إجمالي العينة & \\
\hline
\end{tabular}

المصدر:- بيانات الجدول رقم (5).

(1) تقدير الهامش التسويقي لكل من المنتج وتاجر الجملة في مسالك تسويق محصول القمح - في المسلك التسويقي الأول (منتج- تاجر الجملة- البنك):- وفي هذا المسلك ينتقل المحصول

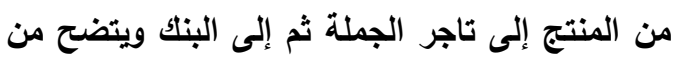

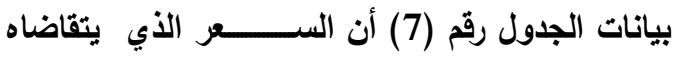

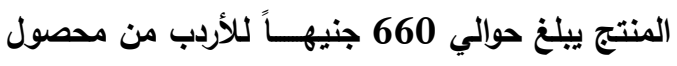

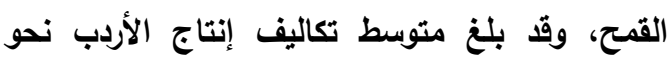
597 جنيهاً، أي أن متوسط الهامش التسويقي للمنتج حوالي 63 جنيهًا أما السعر الذي يتقاضاه تاجر الجملة

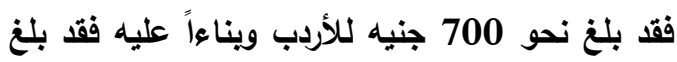

الهامش التسويقي لتاجر الجملة حوالي 40 جنيهاً. - في المسلك التسويقي الثاني (المنتج- البنك): ويتم في هذا المسلك إنتقال المحصول من المنتج إلي البنكا مباشرة ويتضح من بيانات الجدول رقم (7) أن المنتج يتقاضي سعراً مقاره 700جنيها/أردب، وحيث أن أن متوسط تكاليف إنتاج الأردب يبلغ نحو 597 جنيهاً،

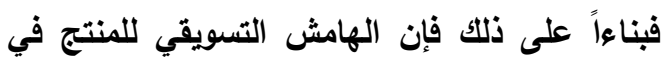
هذا المسلك يبلغ حوالي 103 جنيهاً. - في المسلك التسويقي الثالث (المنتج- المستهلك):يتم إنتقال المحصول من المنتج إلى المستهلك،
تقدير الكفاءة التسويقية في المسالك التسويقية المختلفة لمحصول القمح بعينة البحث:بعد إختيار وتحديد مفردات العينة المختارة من الفئات الحيازية الثلاث لمزارعي محصول القمح بقرى عينة

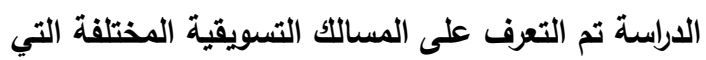
ينتهجونها في تسويق هذا المحصول وتم دراستها وتقدير الكفاءة التسويقية في هذه المسالك. ولتقدير الكفاءة التسويقية يجب معرفة وتقدير كل من الهامش التسويقي وتكاليف إنتاج المحصول. وفيما يلي سوف نتناول كيفية تقير كل من الهامش

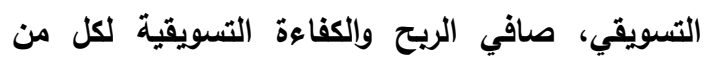

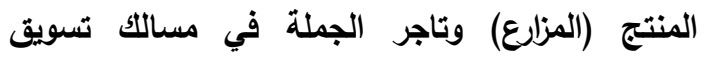
محصول القمح. والهامش التسويقي كما نعلم عبارة عن الفرق بين

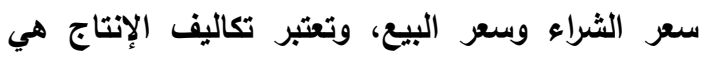

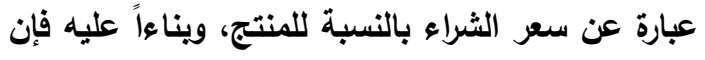
الهامش التسويقي للمنتج من بيعه أربب من القمح عبارة عن الفرق بين سعر بيع الأردب وتكاليف إنتاجه. تقدير كل من الهامش التسويقي، صافي الريح والكفاءة التسويقية لكل من المنتج وتاجر الجملة في مسالك تسويق محصول القمح. 
Sh. A. Ghoneim, et al.,

الكفاءة التسويقية للمنتج (المزار) في المسلك الأول = $100 \times \frac{63}{597+63}-100$

$\% 90.45=9.55-100=100 \times \frac{63}{660}-100=$

الكفاءة التسويقية لتاجر الجملة في المسلك الأول = $100 \times \frac{\dot{40}}{597+40}-100$

$\% 93.72=6.28-100=\frac{4000}{637}-100=$ الكفاعة التسويقية للمنتج في المسلك الثاني $100 \times \frac{88}{597+88}-100$

$\% 87.15=12.85-100=\frac{8800}{685}-100=$

الكفاءة التسويقية للمنتج في المسلك الثالث =

$$
100 \times \frac{103}{597+103}-100
$$

$\% 85.3=14.7-100=\frac{10300}{700}-100=$

تعبر الكفاءة التسويقية عن النسبة بين المنافع

(المخرجات) إلى التكاليف (المدخلات). وتثمل المنافع أو

المخرجات المنافع الزمنية والمكانية والثكلية والتملكية التي تزيد إثباع المستهلك أو المشتري النهائي

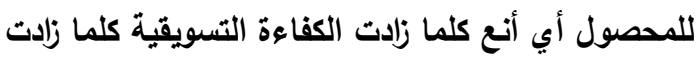
المنافع التي تعود على المستهلك أو التي تعود على المشتري النهائي للمحصول.

ويتضح من النتائج السابقة أن الكفاءة التسويقية في المسلك الأول قد بلغت نحو 90.45\%، 93.72\% لكل من المنتج وتاجر الجملة على الترتيب. أي أن المنافع التي تعود على المشتري النهائي (البنك) كبيرة.
ويتضح من بيانات الجدول رقم (7) أن المنتج يتقاضى سعراً مقداره 700 جنيهاً/ أردب، وحيث أن تكاليف إنتاج الأردب يبلغ نحو 597 جنيهاً، فبناءاً على ذلك فإن الهامش التسويقي للمنتج في هذا المسلك يبلغ نحو 103 جنيهاً.

(1) تقدير صافي الريح لكل من المنتج وتاجر الجملة في مسالك تسويق محصول القمح: - في المسلك التسويقي الأول:- يتضح من بيانات الجدول رقم (7) أن صافي الريح لكل من المنتج وتاجر الجملة قد بلغ نحو 49.5، 22.25 جنيهاً أردب على الترتيب. - في المسلك التسويقي الثاني:- يتضح من_بيانات

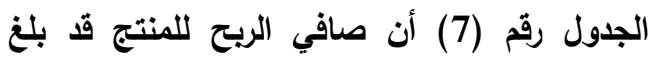
حوالي 70.25 جنيها/أردب. - في المسلك التسويقي الثالث:- يتضح من_بيانات الجدول رقم (7) أن صافي الريح للمنتج يبلغ نحو

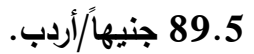

(2) تقدير الكفاءة التسويقية لكل من المنتج وتاجر الجملة في مسالك تسويق محصول القمح: "- تقدير الكفاءة التسويقية في المسلك التسويقي

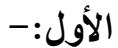

يتضح من بيانات الجدول رقم (7) أن الكفاءة

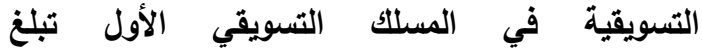
نحو90.45\%، 93.72\% لكل من المنتج وتاجر الجملة على الترتيب، أي أن الكفاءة التسويقية لتاجر الجملة أعلى من مثيلتها للمنتج.

- تقدير الكفاءة التسويقية في المسلكين التسويقيين الثاني والثالث. يتضح من بيانات الجدول رقم (7) أن الكفاءة التسويقية للمنتج في كل من المسلكين التسويقيين الثاني والثالث تبلغ نحو 87.15\%، 85.3\% على الترتيب. 
An economic study of the marketing efficiency of wheat crop in Gharbia ....

ويتضح من بيانات الجدول رقم (8) أن هذه المشكلة

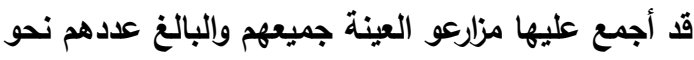

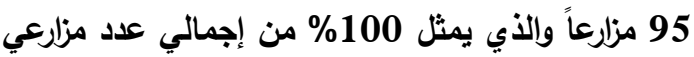

العينة المختارة.

2- تأخر البنك الزراعي أو الجهة الحكومية

المسئولة في تسديد ثمن المحصول للمزارعين :

يتضح من بيانات جدول رقم (8) أن مشكلة تأخر

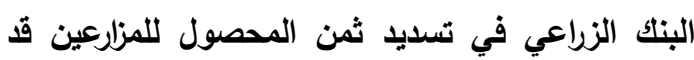

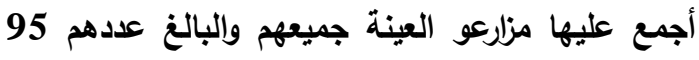
مزارعاً والذي يمثل 100\% من إجمالي عداد مفردات إنهات

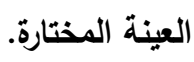

3- تأخر بعض التجار في تسديد ثمن المحصول

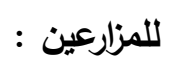

يتضح من بيانات جدول رقم (8) أن عدد مزارعي

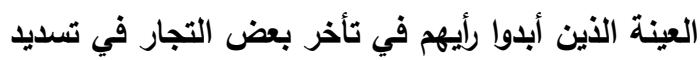

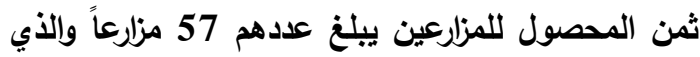
يمثل 60\% من إجمالي عدد مفردات العينة المختارة والبالغ عددهم نحو 95 مفردة.
كما يتضح أن الكفاءة التسويقية للمنتج في المسلك الثاني قد بلغت نحو 87.15\%، وكذا الكفاعة التسويقية للمنتج في المسلك الثالث قد بلغت نحو 85.3\% وكان أهم مشاكل ومعوقات تسويق محصول القمح ومقترحات حلها

يتناول هذا الجزء أهم المشاكل والمعوقات المتعلقة بتسويق محصول القمح والتي حددها مزارعو عينة الاراسة الميدانية المختارة من محافظة الغربية في العام

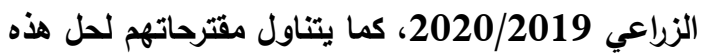
المثاكل والمعوقات والتغلب عليها.

-أهم المشاكل والمعوقات المتعلقة بتسويق محصول القمح: يعاني مزارعو مصصول القمح أثناء تسويقهم لإنتاجهم من هذا المحصول من عدة مشاكل أهمها ما يلي: أ-مشاكل تتعلق بسعر وثمن المحصول: 1-تحكم الحكومة في تحديد سعر شراء المحصول بدئرن

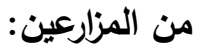

جدول رقم (7): تقدير كل من الهامش التسويقي وصافي الريح والكفاءة التسويقية لكل من المنتج وتاجر الجملة في

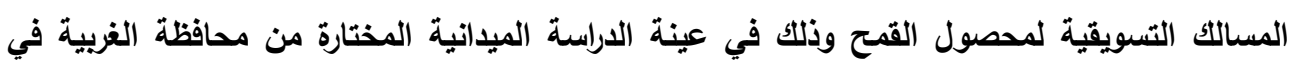

\begin{tabular}{|c|c|c|c|c|c|c|c|c|}
\hline & & & & \multicolumn{5}{|c|}{ الموسم الزراعي 2020/2019. } \\
\hline التسويقية & الريح & التهامش التسويقي & المن بيع & التكاليف & ثمن شراء & متتوسط التكاليف & & \\
\hline$\% 90.45$ & 49.5 & 63 & 660 & 13.5 & 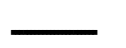 & 597 & المنتج & الأول \\
\hline$\% 93.72$ & 22.25 & 40 & 700 & 17.75 & 660 & $\longrightarrow$ & تاجلة & \\
\hline$\% 87.15$ & 70.25 & 103 & 700 & 17.75 & - & 597 & المنتج & الثاني \\
\hline$\% 85.3$ & 89.50 & 103 & 700 & 13.50 & - & 597 & المنتج & 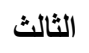 \\
\hline
\end{tabular}

صافي الريح = متوسط الهامش التسويقي - متوسط التكاليف التسويقية. الكفاءة التسويقية = 100 - متوسط الهامش أو الفرق التسويقي + متوسط التوالت الفرق التسويقيف الإنتاجية 
Sh. A. Ghoneim, et al.,

المصدر: جمعت وحسبت من تفريغ إستمارات إستبيان العينة الميدانية. جدول رقم (8): المشاكل التي تتعلق بسعر وثمن المحصول بعينة الداسة الميدانية المختارة من محافظة الغربية في العام الزياعي 2020/2019.

\begin{tabular}{|c|c|c|c|}
\hline \% من عدد مفردات العينة & العدد & 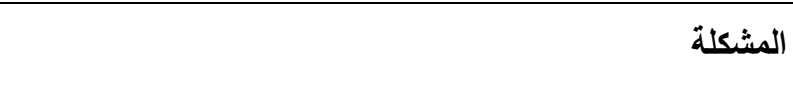 & م \\
\hline$\% 100$ & 95 & تحكم الحكومة في تحديد سعر شراء المحصول من المزارعين & 1 \\
\hline$\% 100$ & 95 & تأخر البنك الزراعي أو الجهة الحكومية المسئولة في تسديد ثمن & ب \\
\hline$\% 60$ & 57 & تأخر بعض التجار في تسديد ثمن المحصول للمزارعين & ج \\
\hline
\end{tabular}

المصدر:- جمت وحسبت من تفريغ بيانات إستمارات إستبيان العينة الميدانية.

اللازمة لتعبئة المحصول بلغ نحو 85 مزارعاً يمثل نحو 90.53 من إجمالي عدد مفردات العينة المختارة

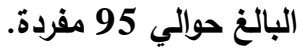

- أهم المقترحات لحل مشاكل تسويق القمح بعينة الدراسة بمحافظة الغربية: بمقابلة أفراد العينة من مزارعي محصول القمح وسؤالهم عن مقترحاتهم لحل المشاكل التي تواجهم في مزاعي تسويق إنتاجهم من محصول القمح، تم التوصل لعديد

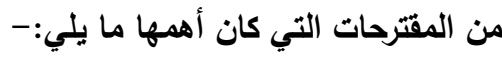

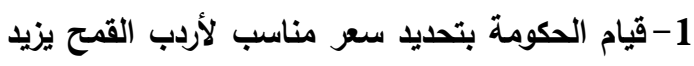
عن تكاليف إنتاجه ويتبقى مبلغ يشجع المزارعين

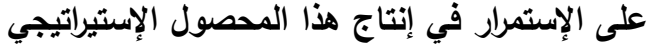

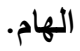
2-قيام الحكومة بحماية المزارعين من تحكم التجار في تحديد سعر شرائهم للمحصول. 3- التوصية بعدم تأخر البنك في تسديد ثمن المحصول. 4-توفير وسائل نقل مناسبة ورخيصة لذامة المزارعين، والعمل على توفير أماكن في القرى لإستلام

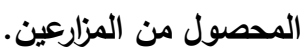

ب - مشاكل تتعلق بالخدمات التسويقية: 1- عدم وجود وسيلة نقل مناسبة ورخيصة يتضح من بيانات الجدول رقم (9) أن عدد مزارعي العينة الذين نقلوا لنا معاناتهم في عدم وجود وسيلة نقل مناسبة ورخيصة لنقل المحصول إلى أماكن البيع سواءًا

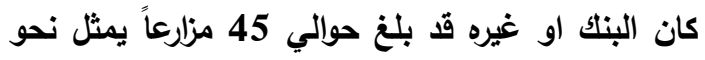
47.37 من إجمالي عدد مفردات العينة المختارة

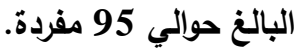
2- بعد المسافة بين المزارع وشونة البنك الزراعي أو جهة التوريد الحكومية يتضح من بيانات الجدول رقم (9) أن عدد مزارعي العينة الذين أبلغونا بأن بعد المسافة بين المزارع وشونة البنك الزراعي يمثل مشكلة تعوقهم في تسويق محصولهم

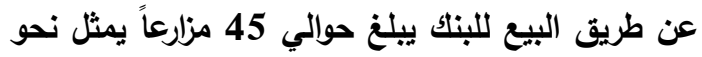
47.37 من إجمالي عدد مفردات العينة المختارة

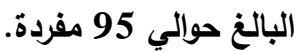
3-عدم توافر العبوات اللازمة يتضح من بيانات الجدول رقم (9) أن عدد مزارعي العينة الذين أبلغونا بمعاناتهم من عدم توافر العبوات 
An economic study of the marketing efficiency of wheat crop in Gharbia ....

جدول رقم (9): المشاكل التي تتعلق ببعض الذدمات التسويقية في تسويق محصول القمح بعينة الدراسة الميدانية المختارة من محافظة الغربية في العام الزراعي 2020/2019.

\begin{tabular}{|c|c|c|c|}
\hline \%من عدد مفردات العينة & العدد & 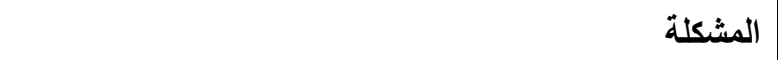 & b \\
\hline$\% 47.37$ & 45 & عدم وجود وسيلة نقل مناسبة ورخيصة & 1 \\
\hline$\% 47.37$ & 45 & العكد المسافة بين المزارع وشونة البنك الزراعي أو جهة التوريد & ب \\
\hline$\% 90.53$ & 85 & عدم توافر العبوات اللازمة لتعبئة المحصول & ج \\
\hline
\end{tabular}

المصدر: جمعت وحسبت من تفريغ بيانات إستمارات إستبيان العينة الميدانية.

ولتقدير الكفاءة التسويقية لابد من تقدير الهامش التسـويقي، وقد تـم تقدير الهامش التسويقي في هذه المسالك لكل من المنتج وتاجر الجملة حيث تبين أن متوسط الهامش التسويقي للمنتج في المسلك التسويقي الأول قد بلغ نحو 63 جنيهاً عند بيعه للأردب الواحد في في لمئي حين بلغ متوسط الهامش التسويقي لتاجر الجملة حوالي فئي 40 جنيهاً في نفس المسلك. أمسا في المسلكين الثاني والثالث فقد بلغ متوسط الهامش التسويقي للمنتج نحو 88، 103جنيهاً في كل من المسلكين على الترتيب. أما فئاف

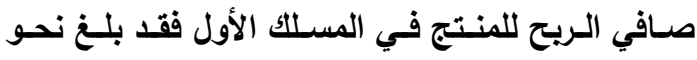

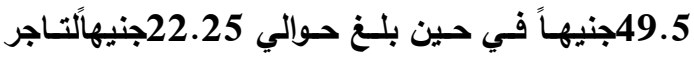
الجملة، أما في المسلكين الثاني والثالث فقد بلـغ صافي الريح للمنتج حوالي 70.25، 89.5 جنيهاً في كل من الجن المسلكين على الترتيب. وقد تم تقدير الكفاءة التسويقية في المسالك التسويقية الثلاثـة حيث بلغت في المسلك الأول نحو 90.45\%، 93.72\% لكل من المنتج وتاجر

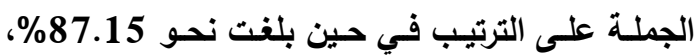

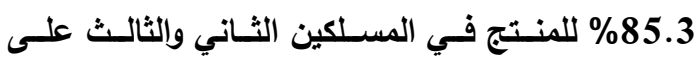
الترتيب.

أما عن أهم مشاكل ومعوقات تسويق محصول القمـح فتضم مجموعتين الأولى تتعلق بسعر وثمن المحصول وتثمل تحكم الحكومة في تحديد سعر الثراء، تأخر البنك

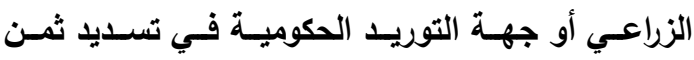

ملخص البحث تناول هذا البحث دراسة اقتصادية للمسالك التسويقية

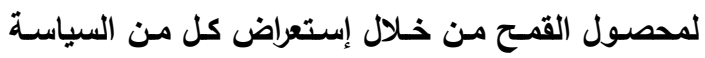
التسـويقية لمحصــول القـــح، كيفيـة تقــير الكفــاءة

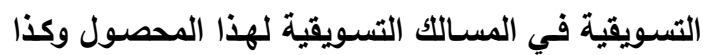
مشـاكل ومعوقات تسويقه ومقترحات حل هذه المشـاكل.

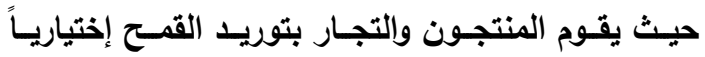

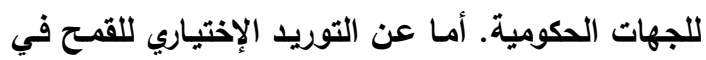

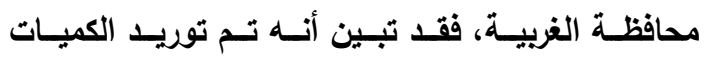
145.26، 137.98، 134.23 ألف طن إلى كل من الجهات الثُلاثة وهي البنك الزراعي المصري، المطاحن والمصرية القابضة للصوامع وتقاضي المنتجون والتجار ثمن ما يتم توريده للاولة حسب السعر التأثيري النوعي. وحسب درجة الجودة، وهذا المتبع في محافظة الغربية يتم إتباعه على المستوى القومي. ولتقــير الكفــاءة التسـويقية لمحصــول القـــح تـم إختيار عينة عشوائية من نحو 95 مزارعاً من مزارعي هذا المحصول مـن محافظة الغربيـة تثــل ثـلاث فئسات حيازية ويتم تسويق المحصول في ثلاث مسالك تسويقية، في المسلك الأول ينتقل المحصول من المنتج إلى تاجر

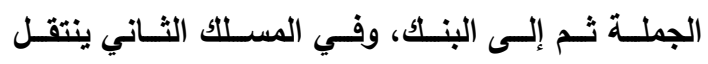
المحصول من المنتج إلى البنك مباشرة، أمسا في المسلك الجكي الثالث فينتقل المحصول من المنتج إلى المستهلك. 
Sh. A. Ghoneim, et al.,

كافي، حيث يثجع ذلك المزارعين على زراعة هذا المحصول، ويالتالي تقل الكميات المستوردة منه مما يؤدي إلى تقليل العجز في ميزان المدفوعات. 4- يجب قيام الحكومة بتحديد سعر مناسب لأردب القمح لئح

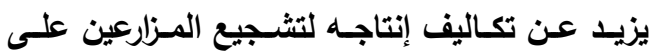
الإستمرار في إنتاجه.

5- توفير وسائل النقل المناسبة (السريعة والرخيصة). 6- من الأفضل للمنتج بيع المحصول للمستهلك مباشرة ويلي ذلك البيع للبنك.

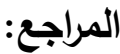

1-ابراهيم صديق على (دكتور). مذكرات في نظرية

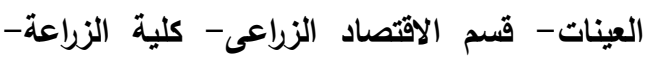
جامعة المنوفية-1994م.

2-أحمد حسن عبد المنعم (دكتور)، إنتاج محاصيل،

الدار العربية للنشر والتوزيع، القاهرة، 1992.

3-إمام محمود الجمسي (دكتور)، دورة تحليل السياسات

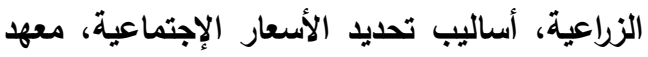

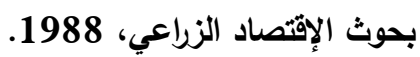

4-مديرية الزراعة بالغريية- الإدارة العامة لثئون

التعاون الزراعي وجميع الأقسام والإدارات التابعة

للمديرية - بيانات غير منشورة ، أعداد مختلفة.

5-وزارة الزراعة وإستصلاح الأراضي- نشرة الثئون

الإقتصادية- نشرة الميزان الغذائي - أعداد مختلفة.

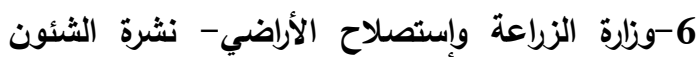

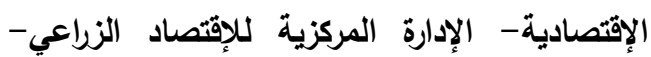

سجلات الإدارة العامة للإحصاءات الزراعية- بيانات

غير منثورة، أعداد مختلفة.
الثراء، وتأخر بعض التجار في تسديد ثمن المحصول

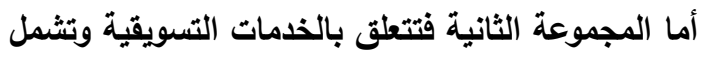
عدم وجود وسيلة نقل مناسبة ورخيصة، بعد المسـافة

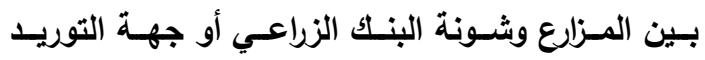
الحكومية وعدم توافر العبوات اللازمة لتعبئة المحصول.

أما عن أهم المقترحات لحل تلك المشـاكل من وجهة نظر المزارعين فكانت عبارة عن قيام الحكومسة بتحديد

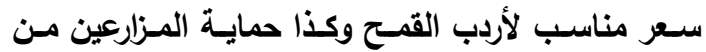

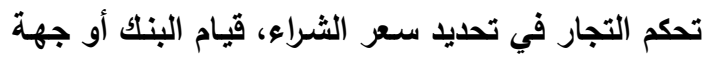
التوريـــ الحكوميـة بتســيد ثمـن المحصــول للمـزارعين

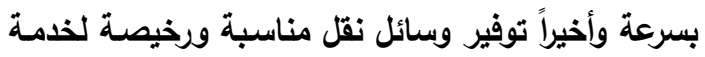
المزارعين، والعمل على توفير أمساكن في القرى لإستلام

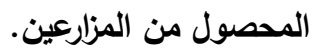
التوصيات

في ضوء مـا أسفر عنه البحث من نتائج ولمواجهة الزيادة الكبيرة في عدد السكان التي تزيـ نسبتها عن فن

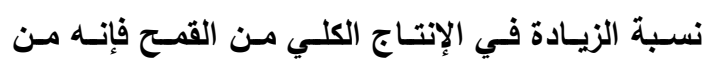
الضروري زيادة التنمية الزراعية للعمل على زيادة إنتاج المحاصيل الزراعيـة بصفة عامـة والقــح بصفة خاصـة ويناءاً عليه فإن البحث يوصي بما يلي:1 - تـوفير مستلزمات الإنتاج ودعمهـا للمـزارعين عن طريق التعاونيات.

2- إنثـاء جمعيات تسويقية على مستوى كل محافظة

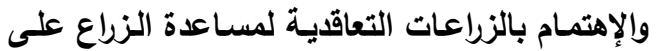
التعرف على كل المعلومات التسويقية. 3- يقوم المتخصصون بالسياسة السعرية الزراعية بتحديد الحد الأدنى من السعر المزرعي بحيث يقارب بالئه

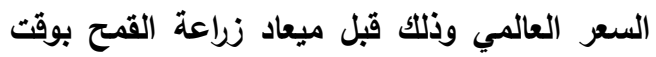




\title{
AN ECONOMIC STUDY OF THE MARKETING EFFICIENCY OF WHEAT CROP IN GHARBIA GOVERNORATE
}

\author{
Sh. A. Ghoneim, M. A. Mubarak, Mofida E. Kabeel and Hala S. Harby \\ Agricultural Research Center - Agricultural Economics Research Institute
}

\begin{abstract}
This Research deals with the economics of marketing the wheat crop by reviewing both the marketing policy of the wheat crop, how to estimate the marketing efficiency in the marketing pathways of this crop, as well as it's the marketing problems and obstacles and proposals for solving these problems, Producers and traders supply wheat voluntarily to government agencies. As for the voluntary supply of wheat in the Gharbia governorate, it was found that the quantities of 145.26, 137.99 and 134.24 thousand tons were supplied to each of the three entities, which are the Egyptian Agricultural Bank, the mills and the Egyptian Silos Holding Company, and the producers and traders charge the price of what is supplied to the state according to the specific indicative price. According to the degree of quality, this practice in Gharbia Governorate is followed at the national level.

To assess the marketing efficiency of the wheat crop, a random sample of about 95 farmers of this crop was chosen from the Gharbia governorate, which includes three holding categories. The crop is marketed in three marketing channels, in the first route the crop moves from the producer to the wholesaler then to the bank, and in the second route the crop moves From the producer to the bank directly, as for the third route, the crop is transferred from the producer to the consumer.

In order to estimate the marketing efficiency, the marketing margin must be estimated, and the marketing margin in these routes has been estimated for both the producer and the wholesaler, as it was found that the average marketing margin for the product in the first marketing course was about 63 pounds when it was sold to one ard, while the average marketing margin for the wholesaler was about 40 pounds for the same lane. As for the second and third trends, the average marketing margin for the product reached 88 and 103 pounds in each of the two tracks, respectively. As for the net profit of the producer in the first route, it amounted to about 49.5 pounds, while it amounted to about 22.25 pounds for the wholesaler, and in the second and third ways, the net profit of the product amounted to about 85.3 and 89.5 pounds in each of the two tracks, respectively.The marketing efficiency was estimated in the three marketing channels, as it reached about 90.45 and $93.72 \%$ for the producer and wholesaler in the first route, while it reached about $\mathbf{8 7 . 1 5 \%}$ and $\mathbf{8 5 . 3 \%}$ for the product in the second and third tracks, respectively.
\end{abstract}

As for the most important problems and obstacles to marketing the wheat crop, it includes two groups. The first is related to the price of the crop and includes government control in determining the purchase price. And cheap, given the distance between the farms and the agricultural bank's stall, and the unavailability of the necessary packaging to fill the crop.

As for the most important proposals to solve these problems from the farmers 'point of view, the government set an appropriate price for wheat ard, as well as protecting farmers from merchants' control in determining the purchase price, the bank would pay the price of the crop to farmers quickly and finally provide suitable and cheap transportation to serve farmers, and work to provide places In the villages to receive the crop from the farmers.

Key words: The marketing efficiency, the marketing pathways, the marketing margin, the problems and obstacles.

أسماء السادة المحكمين

أ.د/ أنور على مرسى لبن كلية الززاعة - جامعة الزقازيق، أ.د/ صبحى أحمد أبو النجا كلية الزراعة - جامعة المنوفية 